\title{
Flow Field and Acoustic Predictions for Three-Stream Jets
}

\author{
Shaun P. Simmons ${ }^{1}$, Brenda Henderson ${ }^{2}$ and Abbas Khavaran ${ }^{3}$ \\ NASA Glenn Research Center, Cleveland, Ohio 44135
}

\begin{abstract}
Computational fluid dynamics was used to analyze a three-stream nozzle parametric design space. The study varied bypass-to-core area ratio, tertiary-to-core area ratio and jet operating conditions. The flowfield solutions from the Reynolds-Averaged Navier-Stokes (RANS) code Overflow 2.2e were used to pre-screen experimental models for a future test in the Aero-Acoustic Propulsion Laboratory (AAPL) at the NASA Glenn Research Center (GRC). Flowfield solutions were considered in conjunction with the jet-noise-prediction code JeNo to screen the design concepts. A two-stream versus three-stream computation based on equal mass flow rates showed a reduction in peak turbulent kinetic energy (TKE) for the three-stream jet relative to that for the two-stream jet which resulted in reduced acoustic emission. Additional three-stream solutions were analyzed for salient flowfield features expected to impact farfield noise. As tertiary power settings were increased there was a corresponding near nozzle increase in shear rate that resulted in an increase in high frequency noise and a reduction in peak TKE. As tertiary-to-core area ratio was increased the tertiary potential core elongated and the peak TKE was reduced. The most noticeable change occurred as secondary-to-core area ratio was increased thickening the secondary potential core, elongating the primary potential core and reducing peak TKE. As forward flight Mach number was increased the jet plume region decreased and reduced peak TKE.
\end{abstract}

$\begin{array}{ll}x, Z & =\text { axial and radial dimensions } \\ M_{\infty} & =\text { freestream Mach number } \\ T_{\infty} & =\text { freestream static temperature } \\ A_{c} & =\text { core nozzle exit area } \\ A_{b} & =\text { bypass nozzle exit area } \\ A_{t} & =\text { tertiary nozzle exit area } \\ N P R_{c} & =\text { core stagnation pressure to freestream total pressure ratio } \\ N P R_{b} & =\text { bypass stagnation pressure to freestream total pressure ratio } \\ N P R_{t} & =\text { tertiary stagnation pressure to freestream total pressure ratio } \\ N T R_{c} & =\text { core stagnation temperature to freestream total temperature ratio } \\ N T R_{b} & =\text { bypass stagnation temperature to freestream total temperature ratio } \\ N T R_{t} & =\text { tertiary stagnation temperature to freestream total temperature ratio } \\ U & =\text { axial jet velocity } \\ U_{\text {jet }} & =\text { core jet axial peak velocity } \\ T K E & =\text { turbulent kinetic energy } \\ D_{\text {core }} & =\text { effective core exit area diameter }\end{array}$

\footnotetext{
${ }^{1}$ Researcher, Inlet and Nozzle Branch, MS VPL-3, 21000 Brookpark Rd., Cleveland OH 44135. AIAA Fellow.

${ }^{2}$ Researcher, Acoustic Branch, MS 54-3, 21000 Brookpark Rd., Cleveland OH 44135. AIAA member.

${ }^{3}$ Researcher, Acoustic Branch, MS VPL-3, 21000 Brookpark Rd., Cleveland OH 44135. AIAA member.
} 


\section{Introduction}

TUTURE turbine-engine architectures are beginning to focus on providing a third exhaust stream for noise1 reduction potential. Introducing the third stream as an additional bypass stream allows for the reduction of the velocity shear rate between the outer jet stream and the ambient air (thus modifying turbulent kinetic energy) and alters the length of the secondary potential core, both effects having a possible impact on the radiated noise. Additionally, a third stream provides flexibility that can assist in balancing the requirements of thrust and noise reduction. However, the flow and noise characteristics of three-stream jets are not well known. Some previous investigations focused on the use of a third-stream to improve shock and shock-noise characteristics of multi-stream jets or investigated mixing noise characteristics for subsonic jets over a very narrow range of jet area ratios ${ }^{1,2}$. The current study investigates the flow-field and predicted jet noise of three-stream jets over a range of nozzle area ratios using Reynolds-Averaged Navier-Stokes (RANS) computational fluid dynamics (CFD) flow solutions and RANSbased noise prediction tools. The computational results presented here have been used to pre-screen designs for a follow-on experimental investigation. The intent of the overall research effort is the development of a three-stream jet-noise prediction tool for future system studies.

Significant investigations into dual-stream jet noise have been conducted by several researchers contributing to an improved understanding ${ }^{3-6}$. Bogey and Bailly ${ }^{3}$ investigated subsonic jets focusing on cross-correlations of radiated sound pressure and turbulence signals along the jet axis and shear layer. They found the maximum correlation was on the jet axis just at the end of the potential core and signals tended to fall off at large emission angles. Their results suggest a noise generation mechanism near the end of the potential core on the jet centerline was important but diminishes in the sideline direction. In addition, the signals of turbulence at the end of the jet core show that the source of noise is characterized by a dominant low-Strouhal-number over a large axial distance with periodic and intermittent vortical structures into the jet core that was expected to be the turbulent phenomenon in noise generation. Viswanathan, Czech and Lee ${ }^{4}$ performed experimental investigations into dual-stream jet noise focusing on varying both primary and secondary area ratios and flight conditions. Several key findings were obtained starting with varying secondary to primary bypass area ratios (BPR) at different power settings. They point out that the results for noise comparisons were not at constant thrust due to the differing area ratios. They conclude as the BPR increases with increased area ratio (by reducing the core exit area) there is a reduction in peak noise level in the aft quadrant and the high frequency portion of the spectra was generated by the secondary shear layer (note an opposite effect would be found if core area exit was fixed and bypass was increased). Next they analyzed varying jet operating conditions by varying secondary nozzle pressure ratio (NPR), again not on an equal thrust basis. They found three distinct trends in the aft angles of sound spectra, progressively increasing sound pressure levels at lower frequencies with increasing mixed jet velocity, progressively increasing sound levels at higher frequencies with increasing secondary jet velocity and finally a reduction in sound pressure levels of mid-frequencies due to cancellation effects from the different sources as NPR was increased. An important finding observing spectral characteristics at lower angles was there appeared to be no change in spectral shape regardless of jet conditions or geometric parameters. They suggest the properties of fine-scale random turbulence are universal for similar jet flows and the noise generated by this source should also be universal. Finally they analyzed the effects of forward flight and concluded the results lead to a near-uniform reduction in sound level at all frequencies at low polar angles for increasing Mach number ${ }^{5}$. Saxena and Morris ${ }^{6}$ investigated numerical results for single and dual-stream jets in flight using a variety of computational methods. They found for the dual-stream nozzle the fan flow reduces the growth of the primary shear layer and elongated the primary potential core. Jet mixing noise was produced primarily at the end of the potential core hence noise sources were pushed further downstream in the dual-stream as compared to the single stream jet. The addition of a third-stream configuration could additionally impact the secondary-primary potential core in a similar fashion.

The purpose of the current computational analysis is to screen designs for a follow-on experimental investigation that will focus on the acquisition of a comprehensive three-stream flowfield and noise database and the development of associated noise prediction models. Computational results were used to screen designs for unwanted shocks and separations within the nozzles as well as identify design features impacting peak turbulent kinetic energy levels and potential core length. The computational results will also be used for as input for of acoustic-analogy type noise prediction codes that will be used in future system studies. 


\section{Computational Procedure}

The Reynolds-Averaged Navier-Stokes (RANS) code OVERFLOW 2.2e, was used to create and analyze pointmatched overset ${ }^{7}$ structured grids for three-stream nozzle flows. The computations employed the Menter shear stress transport (SST) turbulence model along with a Roe ${ }^{8}$ upwind scheme with an ARC3D flux split Jacobian algorithm. Given symmetry conditions, the grid topology was chosen to be two-dimensional to save computational time and expense. Figure 1 shows the range of geometric parameters. In Figure 1, the nozzle exit area is designated by A and the subscripts c, b, and t indicate the core, bypass, and tertiary streams, respectively. Figure 2 shows the nozzle system used in the study. The parameter selection was based on results from previous system studies conducted for future supersonic commercial aircraft (NASA's N+2 configurations) ${ }^{2}$. The nozzle system includes three externallymixed-convergent nozzles and an external plug.

The flow conditions used in the investigation are shown in Table 1. The nozzle pressure ratio (NPR) is the ratio of the jet-stagnation pressure to the ambient pressure. The nozzle-temperature ratio (NTR) is the ratio of the jetstagnation temperature to the ambient temperature. For all simulations, $\mathrm{NTR}_{\mathrm{b}}=\mathrm{NTR}_{\mathrm{t}}=1.25$ and $\mathrm{NTR}_{\mathrm{c}}=3.2$. Conditions with velocity inversion on the tertiary stream $\left(\mathrm{NPR}_{\mathrm{t}}>\mathrm{NPR} \mathrm{b}\right)$ were included in the investigation.

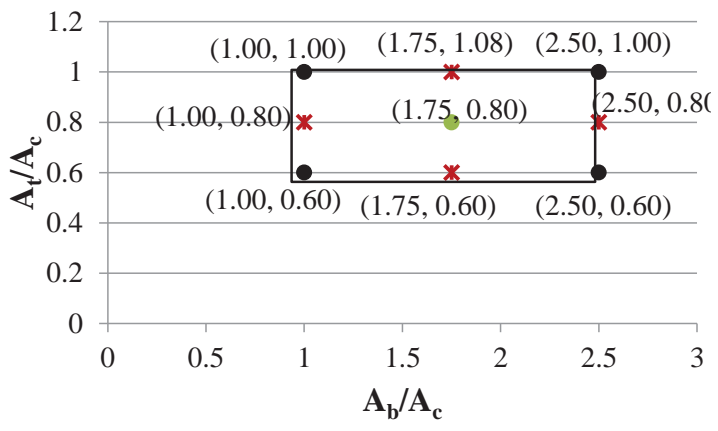

Figure 1. A plot of the geometric design space used in the three-stream study. The blue symbol indicates the hardware configuration used in previous studies ${ }^{2}$.

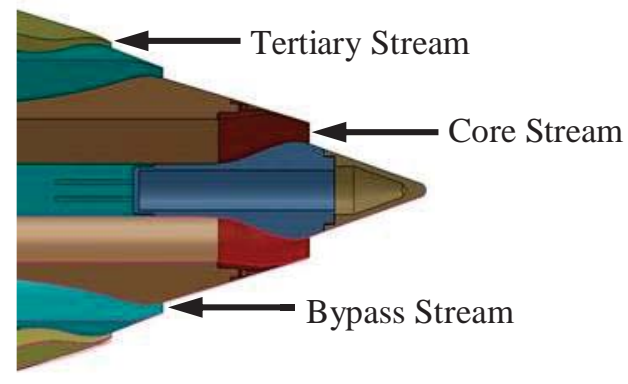

Figure 2. A schematic of the three-stream nozzle system.

Table 1 Jet Conditions

\begin{tabular}{|c|c|c|}
\hline Flow Parameter & Low Level & High Level \\
\hline $\mathrm{NPR}_{\mathrm{b}, \mathrm{c}}$ & 1.5 & 1.8 \\
$\mathrm{NPR}_{\mathrm{t}}$ & 1.3 & 2.4 \\
$\mathrm{NTR}_{\mathrm{c}}$ & 1 & 3.2 \\
$\mathrm{BPR}_{\text {tot }}$ & 2.5 & 5.5 \\
\hline
\end{tabular}




\section{A. Computational Grid and Boundary Conditions}

The computational grid used for area ratios $A_{b} / A_{c}=1.75$ and $A_{t} / A_{c}=1.00$ is shown in Figure 3. The final grid formation was point matched and overset to account for two level grid sequencing. The two-dimensional planar mesh consisted of 330,000 grid points or 1 million in the full 2-D domain. The overall domain stretched $65 \mathrm{D}_{\text {core }}$ streamwise and $20 \mathrm{D}_{\text {core }}$ stream-normal. All solid surfaces were treated as viscous and integrated to the wall with an off body spacing to yield $y^{+}<1$ values. Figure 4 shows the blocking topology which consisted of seven zones: 1) primary nozzle, 2) secondary nozzle, 3) tertiary nozzle, 4) ambient inflow, 5) tertiary exit, 6) secondary exit and 7) primary exit with plume region. The boundary condition for primary, secondary and tertiary zones 1-3 was nozzle inflow with a set NPR and NTR. The ambient inflow zone 4 used a freestream inflow boundary condition setting Mach and static temperature with a simple pressure ratio upper exit boundary. The tertiary and secondary exit zones 5-6 utilized a simple pressure ratio upper boundary condition and the primary exit and plume zone 7 was axisymmetric along the centerline with a simple pressure ratio on the upper boundary and an extrapolated pressure boundary condition at the exit.

The importance of capturing the correct physics in the near nozzle exit region required significant grid resolution. Additionally the grid needed to be aligned and stretched in high shear layer gradient regions. Extensive grid sensitivity studies were carried out over the course of the designs and an optimum topology was chosen. Blocks 5-7 were assembled from as many as 15 sub-domains to ensure viscous stretching into the shear layer near nozzle exit regions and control streamwise grid stretching ratios progressing downstream into the peak TKE regions.

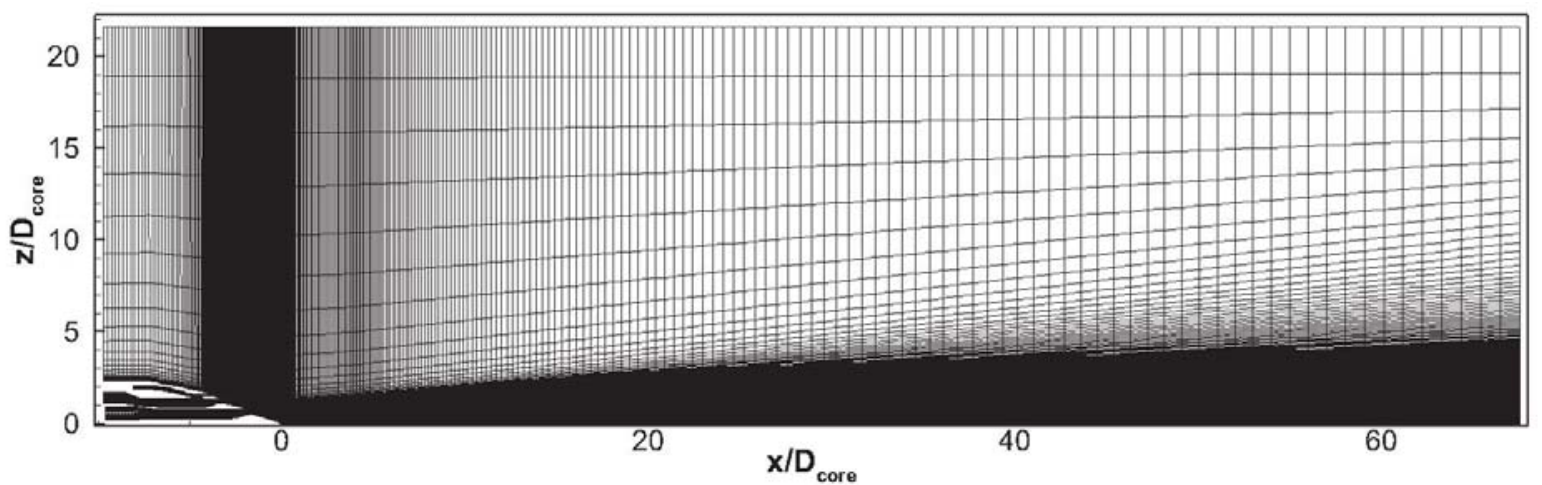

Figure 3. Example computational 2-D mesh and a zoomed nozzle region. Every other point is shown.

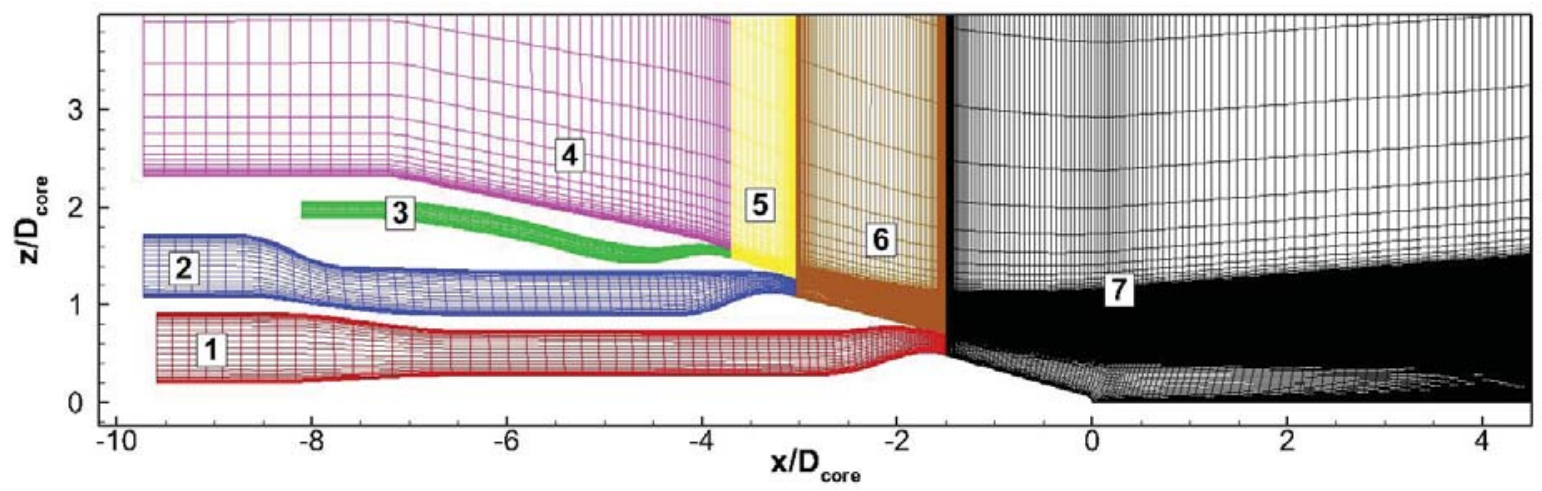

Figure 4. Grid blocking configuration consisting of seven overset zones. 


\section{Results}

The computational solutions for the design space were analyzed by examining Mach number contours, nondimensional axial velocity, and non-dimensional turbulent kinetic energy (TKE). The non-dimensional jet velocity $\mathrm{U} / \mathrm{U}_{\text {jet }}$ is defined as the ratio of the axial velocity $\mathrm{U}$ normalized by the peak primary jet velocity $\mathrm{U}_{\text {jet }}$. The nondimensional turbulent kinetic energy is defined as the ratio of TKE normalized by the peak primary jet velocity squared $\mathrm{U}^{2}$ jet . Axial and radial dimensions have been normalized by the effective core diameter obtained from the core-nozzle exit area.

The nozzle design contours were evaluated to identify flow separation and regions where local shocks formed. Figure 5 shows the design point $A_{b} / A_{c}=A_{t} / A_{c}=1.0$ and $N_{c} R_{c}=N R_{b}=N P R_{t}=1.8$, where the secondary trailing edge location relative to the plug exhibited a sensitivity. As the design moved the secondary trailing edge closer to the plug an internal shock formed, as the secondary trailing edge was relocated upstream from the plug an external shock formed. A shock-free solution was finally obtained by increasing the rate of convergence of the secondary flow path area ratio near the nozzle exit plane.
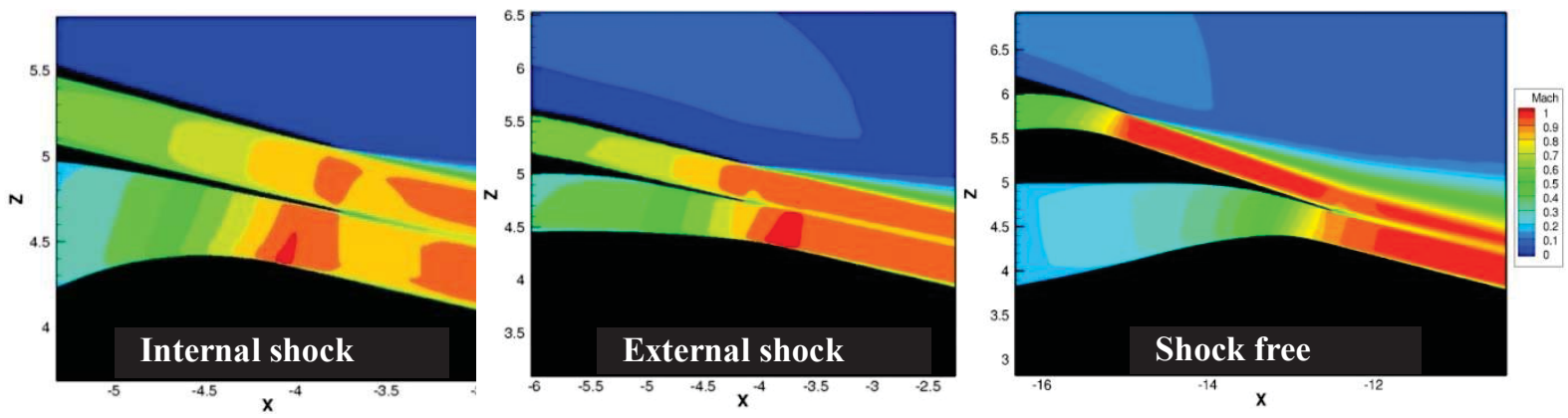

Figure 5. Mach number contour plots taken near the nozzle trailing edges for $A_{b} / A_{c}=A_{t} / A_{c}=1.00$ and for $N P R_{c}=N P R_{b}=N P R_{t}=1.8$. The plots show the impact of bypass-nozzle contouring and trailing edge location on the resulting near-nozzle Mach numbers. Secondary TE location relative to the plug exhibited an internal shock, secondary TE located upstream exhibited an external shock and finally increased rate of convergence for secondary nozzle exit area is shock free.

\section{A. Two-stream Versus Three-stream}

Figure 6 details the secondary and tertiary potential cores which are of importance to understanding the benefits of adding a third stream. The flow features of three-stream configurations consist of a thin shear layer between the primary potential core and secondary bypass potential core, another shear layer between the bypass and tertiary potential core and finally an outer shear layer with the ambient which continues to grow as the tertiary and secondary gradually merge to form a single potential core downstream. The length of the tertiary potential core can have an impact on jet mixing and, therefore, acoustic emission.

To gain a better understanding of the impact of adding a third stream to a dual stream configuration, solutions were obtained for the flowfield of dual-stream and three-stream designs with comparable mass flow rates. The results for a dual-stream configuration with a $\mathrm{A}_{\mathrm{b}} / \mathrm{A}_{\mathrm{c}}$ ratio of $1.00, \mathrm{NPR}_{\mathrm{c}}=1.8$, and $\mathrm{NPR}_{\mathrm{b}}=1.8$ are shown in the upper half of Figures 7 and 8. To match the mass flow rate of the dual stream configuration, a three-stream configuration with $A_{b} / A_{c}=A_{t} / A_{c}=1.00$ was selected and analysis was performed for $\mathrm{NPR}_{c}=\mathrm{NPR}_{b}=1.6$ and $\mathrm{NPR}_{t}$ =1.3. The results for the three-stream nozzle configuration are shown in the lower half of Figures 7 and 8 . As shown by the normalized velocity in Figure 7, the primary potential core length was greater for the three-stream case than for the two-stream case. In Figure 8, the three-stream nozzle produced lower peak turbulent kinetic energy (TKE) levels than those for the two-stream nozzle system and reduced jet exhaust noise across the full spectra, and is shown in the following section IV. 


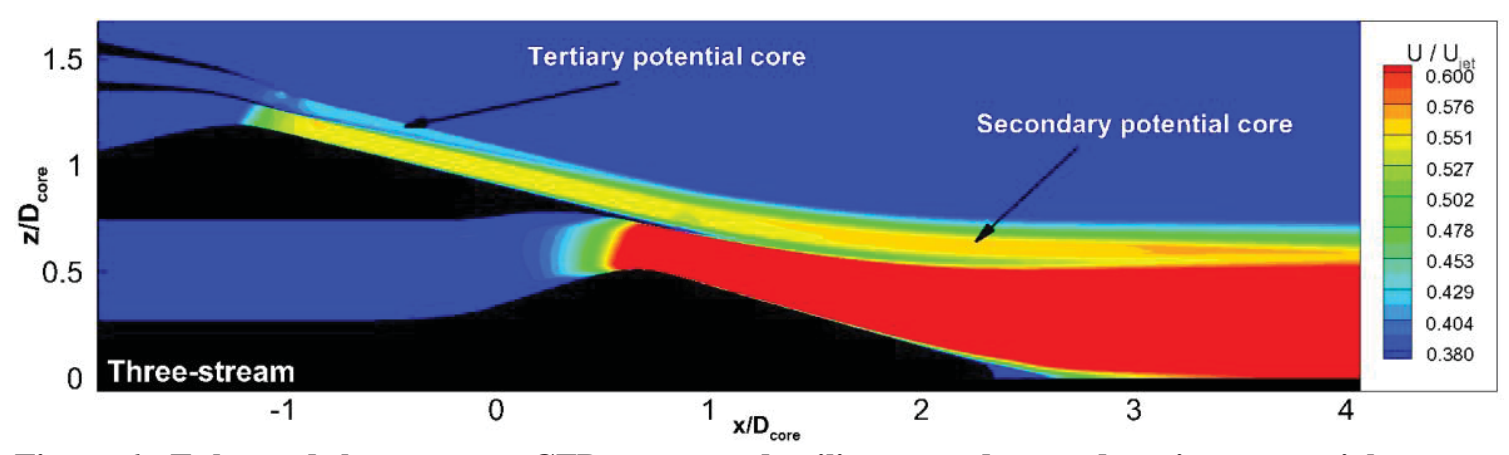

Figure 6. Enhanced three-stream CFD contours detailing secondary and tertiary potential cores at operating conditions.

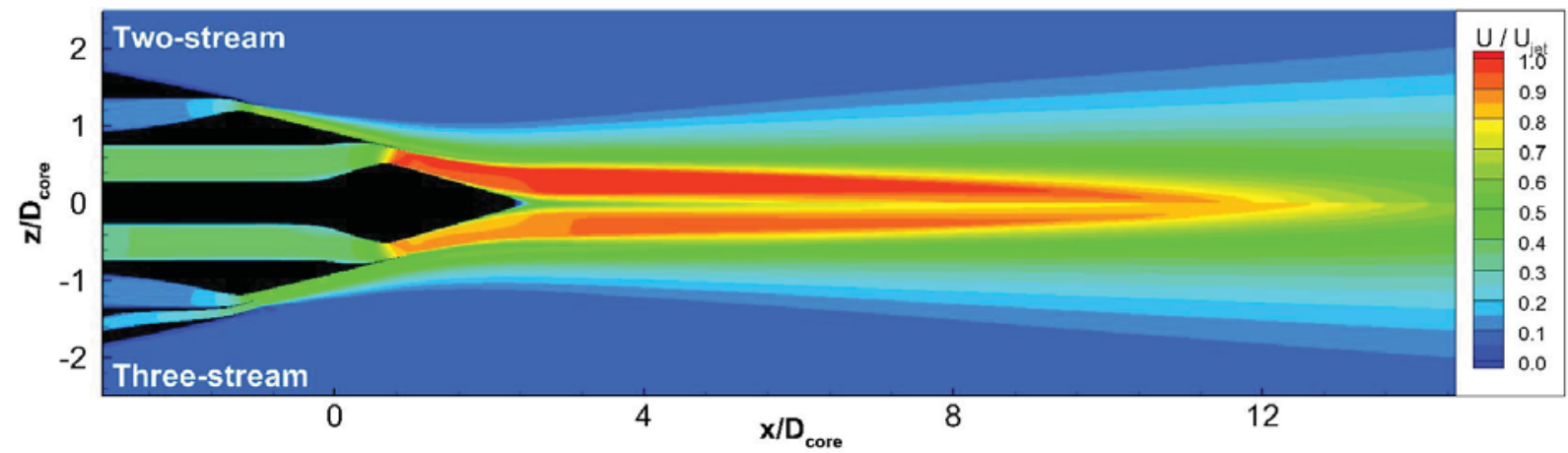

Figure 7. Mean axial velocity predictions. Upper half, two-stream nozzle $\left(A_{b} / A_{c}=1.0, N_{c} R_{c}=1.8, N P R_{b}\right.$ = 1.8); lower half, three-stream nozzle $\left(A_{b} / A_{c}=1.0, A_{t} / A_{c}=1.0, N R_{c}=N P R_{b}=1.6, N R_{t}=1.3\right)$.

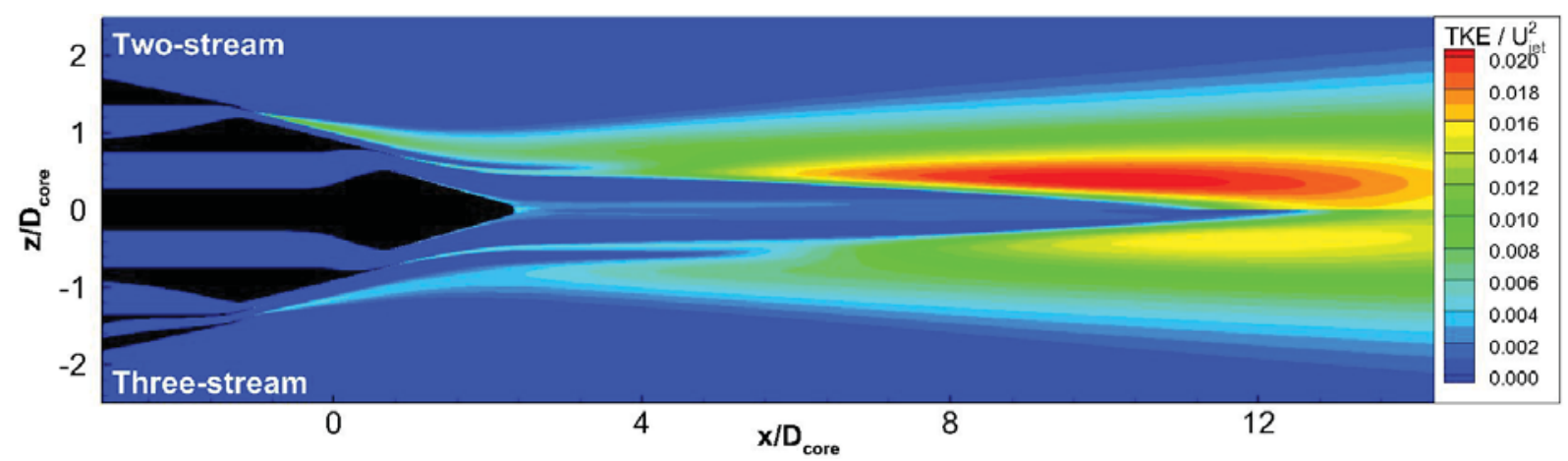

Figure 8. Turbulent kinetic energy predictions. Upper half, two-stream nozzle $\left(A_{b} / A_{c}=1.0, N_{c} R_{c}=1.8\right.$,

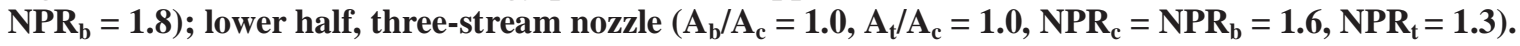




\section{B. Tertiary NPR Variation}

Simulations were performed with varying tertiary power settings to analyze the impact on acoustic emissions. The design point with area ratios $\mathrm{A}_{b} / \mathrm{A}_{c}=1.75, \mathrm{~A}_{\mathrm{t}} / \mathrm{A}_{c}=1.00$ and tertiary power settings was analyzed for varying $\mathrm{NPR}_{t}$ $=1 \cdot 4,1 \cdot 6,1.8$. Both bypass and core flows were held constant at $\mathrm{NPR}_{\mathrm{b}}=\mathrm{NPR}_{\mathrm{c}}=1.8$ simulating a "dual-stream configuration" with a free jet $\mathrm{M}_{\infty}=0.10$. Figure 9 shows the computational results when the tertiary power settings are varied resulting in decreased peak TKE consistent with a previously noted dual-stream study ${ }^{4}$.

Figure 10 shows the axial locations of the cross-stream non-dimensional velocity and non-dimensional TKE to be plotted and analyzed for the previous design point. Analyzing stations along the nozzle geometry can highlight important features of three-stream configurations for potential core lengths and related TKE effects. Since both are important to acoustic levels, insight gained could lead to improved future designs. The stations are normalized with $\mathrm{D}_{\text {core }}$ and the tip of the external plug is at station 0.0 with downstream stations positive valued. Station $-3.1 \mathrm{D}_{\text {core }}$ is located just upstream of the secondary trailing edge to capture the tertiary potential core and ambient shear layer. Station $-2.9 \mathrm{D}_{\text {core }}$ is located just downstream of the secondary trailing edge and exhibits the tertiary potential core and secondary potential core with the shear layer between them and tertiary potential core with ambient shear layer. Stations $-2.7 \mathrm{D}_{\text {core }}$ through $-1.6 \mathrm{D}_{\text {core }}$ track the thinning of the shear layer between the secondary and tertiary potential cores and the eventual merging of the two streams as the tertiary core terminates. Station $-1.4 \mathrm{D}_{\text {core }}$ is located just downstream of the primary trailing edge and captures the primary and secondary potential cores and the shear layer between them. Finally stations $-0.7 \mathrm{D}_{\text {core }}$ through $2.7 \mathrm{D}_{\text {core }}$ track the thinning of the shear layer between the primary and secondary potential cores and the eventual merging into a single primary potential core and shear layer with the ambient.

The velocity profiles at the axial stations defined in Figure 10 are shown in Figure 11 and the TKE profiles are shown in Figure 12. The solutions for $\mathrm{NPR}_{\mathrm{t}}=1.4,1.6,1.8$ are shown as green, blue and red respectively. At station $3.1 \mathrm{D}_{\text {core }}$ in Figure 11,the tertiary potential core is visible along with the shear layer and ambient for each $\mathrm{NPR}_{\mathrm{t}}$. As $\mathrm{NPR}_{\mathrm{t}}$ is increased the tertiary potential core jet velocity increases and results in a decrease in the shear rate (or slope) between the tertiary and ambient flow. At station $-3 \cdot 1 \mathrm{D}_{\text {core }}$ in Figure 12 , the decrease in shear rate results in an increase in peak TKE. At station -2.9D core in Figure 11, both the tertiary and secondary potential cores are visible along with the shear layer between them and the tertiary shear layer and ambient. The tertiary potential core has a slight effect on the secondary potential core as increasing $\mathrm{NPR}_{t}$ causes a reduction in secondary potential core peak jet velocity. By station $-2.7 \mathrm{D}_{\text {core }}$ in Figure 11, the tertiary potential core has minimal effect on the secondary potential core as peak velocities are again similar. Stations $-3 \cdot 1 \mathrm{D}_{\text {core }}$ to $-2.4 \mathrm{D}_{\text {core }}$ in Figure 12 detail the increase in TKE region with the tertiary and ambient shear layer progressing downstream. By station $-2.2 \mathrm{D}_{\text {core }}$ in Figure 11 ,the $\mathrm{NPR}_{\mathrm{t}}=1.4$ tertiary potential core is about to merge with the secondary potential core and appears as a slight kink in the velocity profile as the shear layer between them is reduced. At station $-1.9 \mathrm{D}_{\text {core }}$ Figure 11 , the $\mathrm{NPR}_{\mathrm{t}}=1.6$ tertiary potential core is about to merge with the secondary potential core and finally at station $-1.4 \mathrm{D}_{\text {core }}$ the $\mathrm{NPR}_{\mathrm{t}}=$ 1.8 tertiary potential core has merged with the secondary potential core. $\mathrm{NPR}_{\mathrm{t}}$ has increased tertiary potential core length respectively. At station $-1.4 \mathrm{D}_{\text {core }}$ in Figure 11 , the shear layer between the primary and secondary is visible as well as the primary potential core. By station $-0.7 \mathrm{D}_{\text {core }}$ the addition of the tertiary stream on the primary potential core peak velocity is minimal. The shear layer between the secondary potential core and ambient continues to thicken and by $2.7 \mathrm{D}_{\text {core }}$ the secondary potential core is about to merge to form the primary potential core. $\mathrm{NPR}_{\mathrm{t}}$ continues to thicken the shear layer with the ambient and decrease peak TKE. The primary potential core eventually terminates around $12 \mathrm{D}_{\text {core }}$ where the reduction in peak TKE levels associated with large scale turbulence are expected to have an impact on sound spectra ${ }^{5}$. 


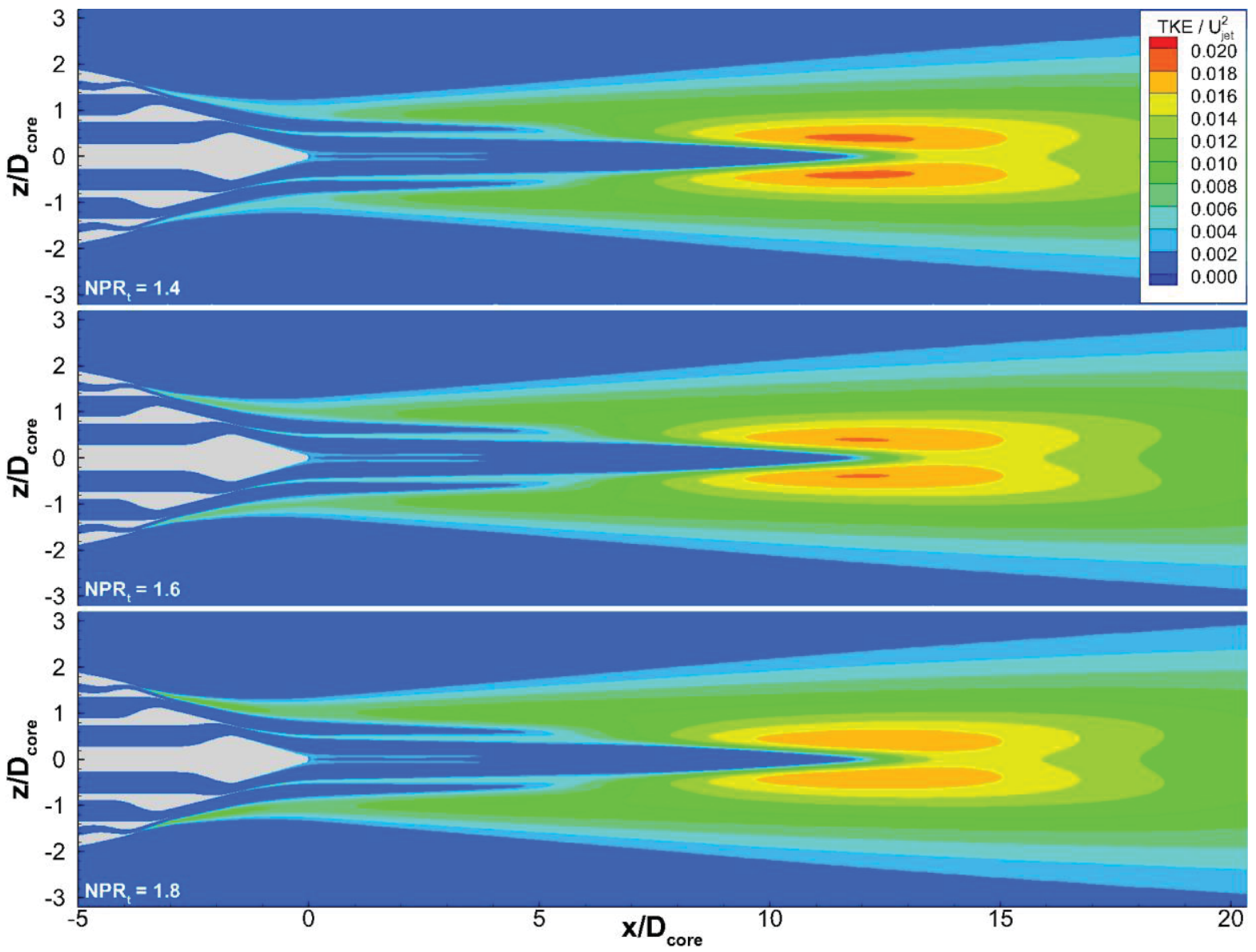

Figure 9. Turbulent kinetic energy in a three-stream nozzle at $\left(A_{b} / A_{c}=1.75, A_{t} / A_{c}=1.00, N P R_{b}=N P R_{c}=\right.$ 1.8, $\mathrm{M}_{\infty}=0.10$ ): $\mathrm{NPR}_{\mathrm{t}}=1.4,1.6,1.8$ from top to bottom.

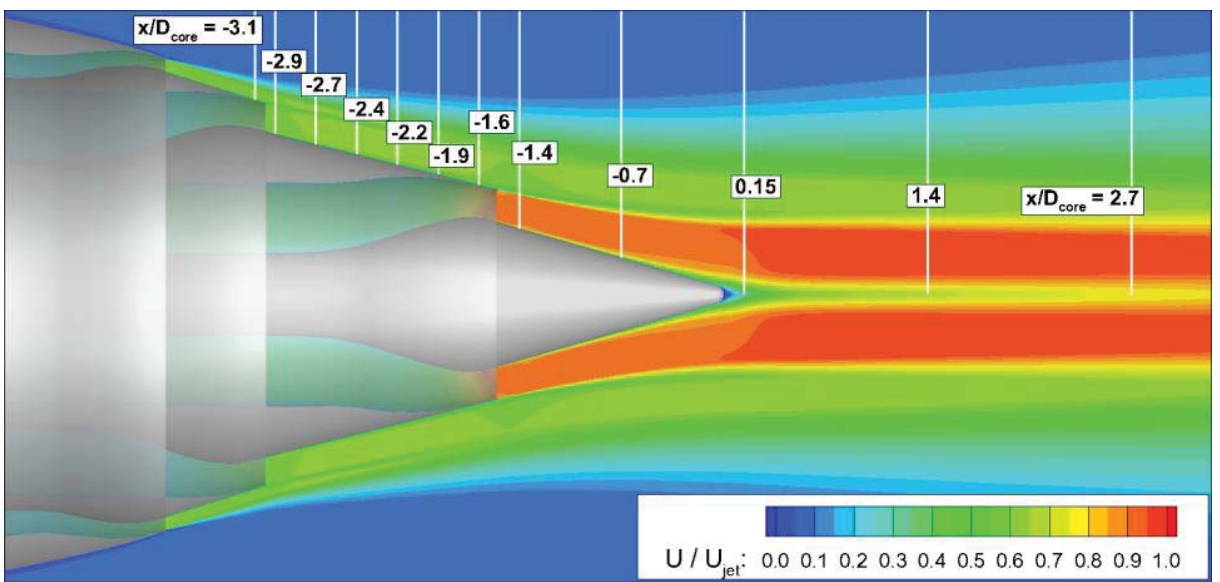

Figure 10. Velocity profile stations. Case $\mathrm{NPR}_{\mathrm{c}}=1.8, \mathrm{NPR}_{\mathrm{b}}=1.8, \mathrm{NPR}_{\mathrm{t}}=1.8$, $A_{b} / A_{c}=1.75$ and $A_{t} / A_{c}=1.00, M_{\infty}=0.10$. 

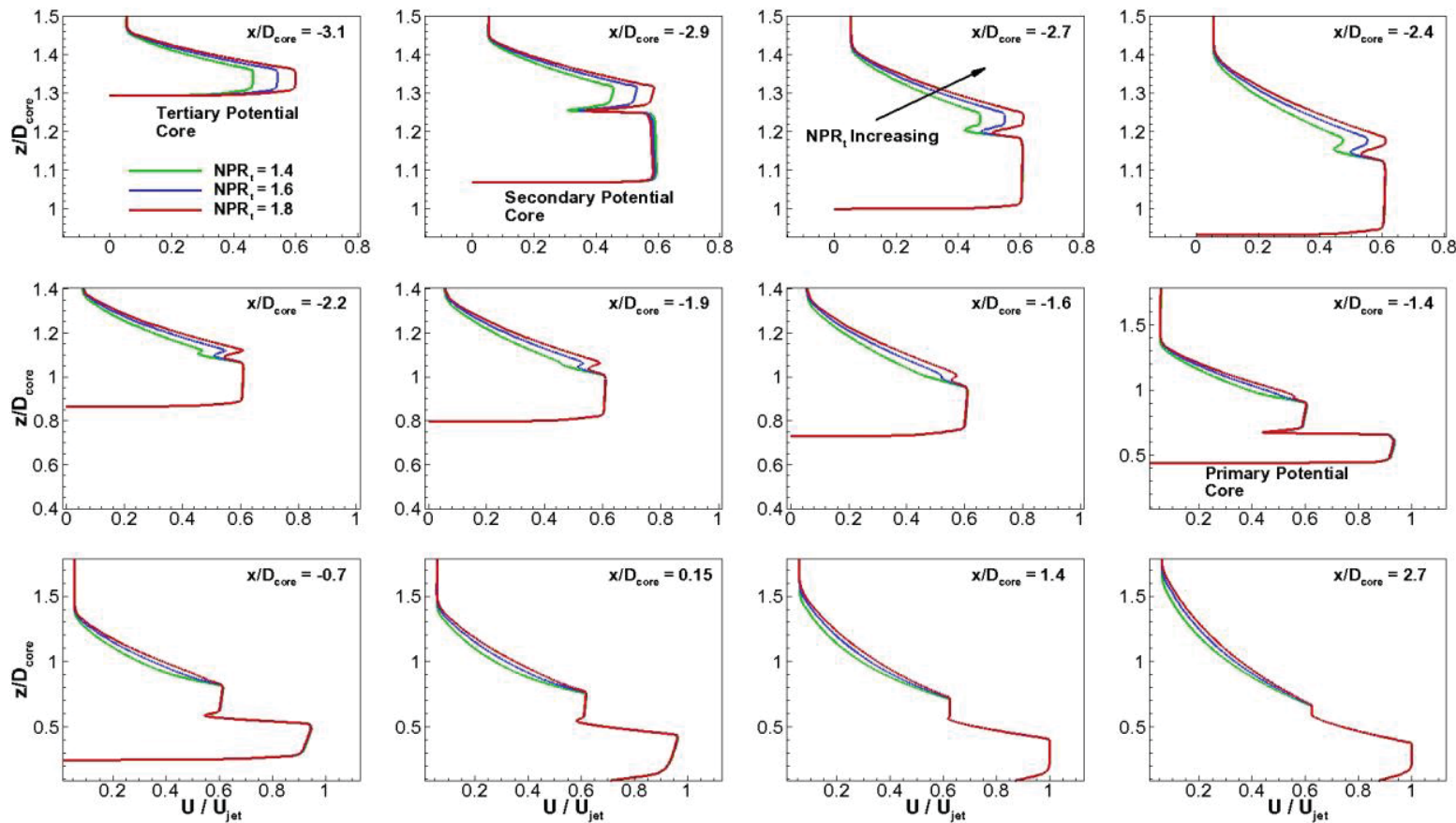

Figure 11. Velocity profiles progressing from near tertiary nozzle trailing edge to $2.7 \mathrm{D}_{\text {core }}$ downstream. Primary, secondary and tertiary potential cores are highlighted for $\mathrm{NPR}_{t}=1.4,1.6,1.8$, $\mathbf{M}_{\infty}=\mathbf{0 . 1 0}$.
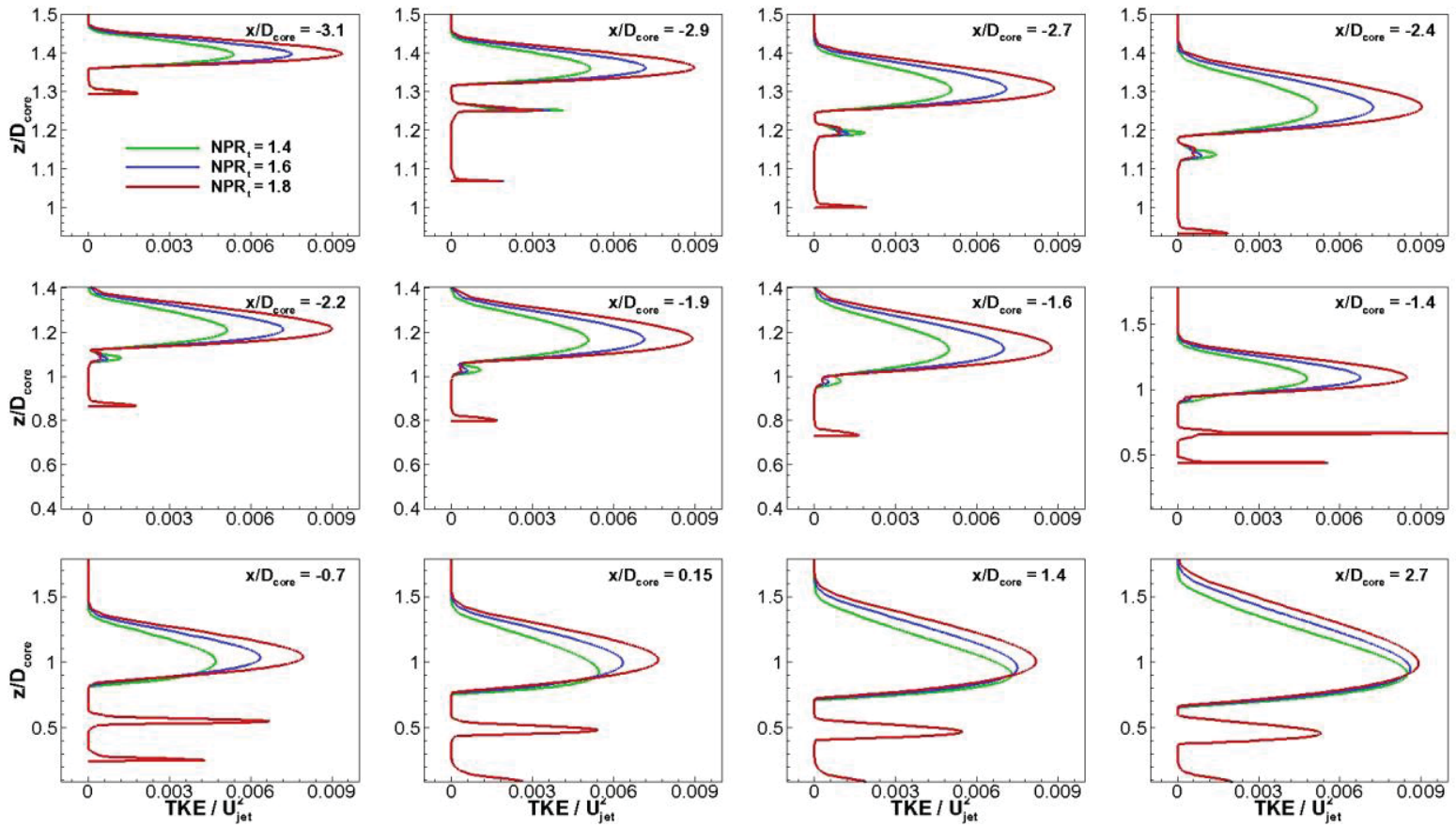

Figure 12. TKE profiles progressing from tertiary nozzle trailing edge to $2.7 \mathrm{D}_{\text {core }}$ downstream. Primary, secondary and tertiary potential cores are highlighted for $\mathrm{NPR}_{\mathrm{t}}=1.4,1.6,1.8$.

9

American Institute of Aeronautics and Astronautics 


\section{Tertiary Area Variation}

The impact of varying tertiary-to-core exit area is analyzed for the design point of area ratio $A_{b} / A_{c}=1.75$, and pressure ratios $\mathrm{NPR}_{t}=1.6, \mathrm{NPR}_{\mathrm{b}}=\mathrm{NPR}_{\mathrm{c}}=1.8$. The tertiary-to-core area ratio $\mathrm{A}_{t} / \mathrm{A}_{\mathrm{c}}$ is varied from $0.40,0.60$ and 0.80 by increasing tertiary exit area with a fixed core exit area and TKE is plotted in Figure 13. As the ratio $A_{t} / A_{c}$ is increased the peak TKE levels decrease in the downstream region near the termination of the primary potential core. In addition, the length of the primary potential core increases with an increase in $A_{t} / A_{c}$ area ratio.

In a similar fashion the axial velocity profiles are plotted in Figure 14 and TKE profiles are plotted in Figure 15 for the $A_{t} / A_{c}$ variation at the defined stations in Figure 10. At station -3.1D core in Figure 14 the area ratio increase appears to translate the outer shear layer and thicken the tertiary potential core. The tertiary peak potential core velocity appears to remain fairly similar across the area variation but changes in tertiary potential core length are evident progressing to station $-1.6 \mathrm{D}_{\text {core }}$. The ratio $\mathrm{A}_{t} / \mathrm{A}_{\mathrm{c}}=0.40$ tertiary potential core merges with the secondary potential core by $-2.7 \mathrm{D}_{\text {core }}$, ratio $A_{t} / A_{c}=0.60$ merges with the secondary potential core by $-2.4 D_{\text {core }}, A_{t} / A_{c}=0.80$ merges by $-1.9 \mathrm{D}_{\text {core }}$ and finally $\mathrm{A}_{\mathrm{t}} / \mathrm{A}_{\mathrm{c}}=1.00$ merges with the secondary potential core by $-1.6 \mathrm{D}_{\text {core }}$. Stations $-3.1 \mathrm{D}_{\text {core }}$ through $-1.6 \mathrm{D}_{\text {core }}$ in Figure 15 show an increase in peak TKE with an increase in $A_{t} / A_{c}$ ratio but by $-1.4 D_{\text {core }}$ the trend begins to reverse and by $2.7 \mathrm{D}_{\text {core }}$ the smaller tertiary-to-core exit area results in a decrease in peak TKE over the larger areas respectively. The smaller tertiary $A_{t} / A_{c}$ ratios when merged with the secondary potential core result in a reduced shear rate as you progress downstream and peak TKE is increased.

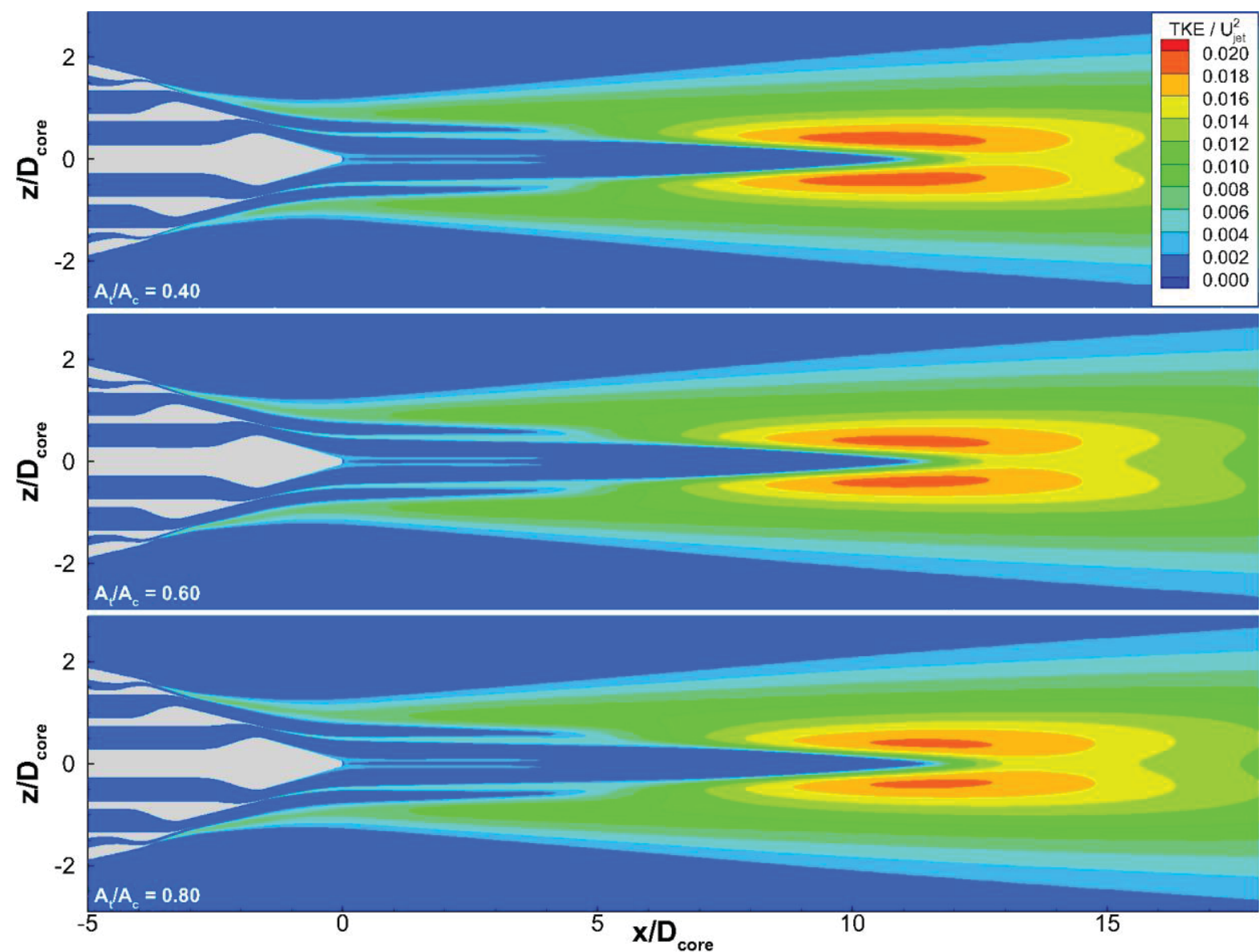

Figure 13. Effect of tertiary area ratio on TKE at $\left(A_{b} / A_{c}=1.75, N P R_{t}=1.6, N P R_{b}=N P R_{c}=1.8\right)$ and sweeping $A_{t} / A_{c}=0.40,0.60,0.80$ from top to bottom. 

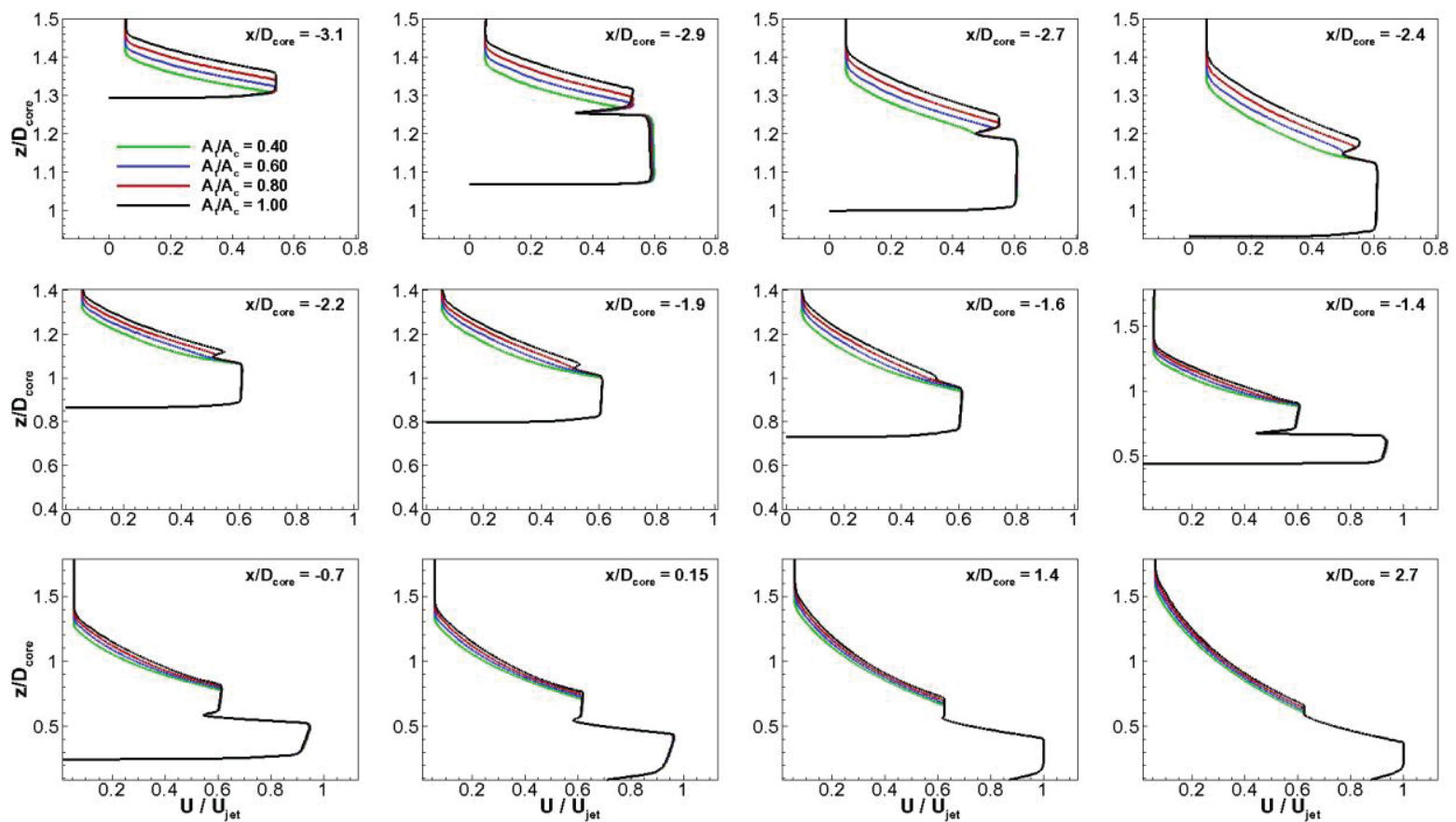

Figure 14. Velocity profiles progressing from tertiary nozzle trailing edge to $2.7 \mathrm{D}_{\text {core }}$ downstream at $\left(A_{b} / A_{c}=1.75, N P R_{t}=1.6, N P R_{b}=N P R_{c}=1.8\right)$. Tertiary area ratios vary as $A_{t} / A_{c}=0.40,0.60,0.80$.
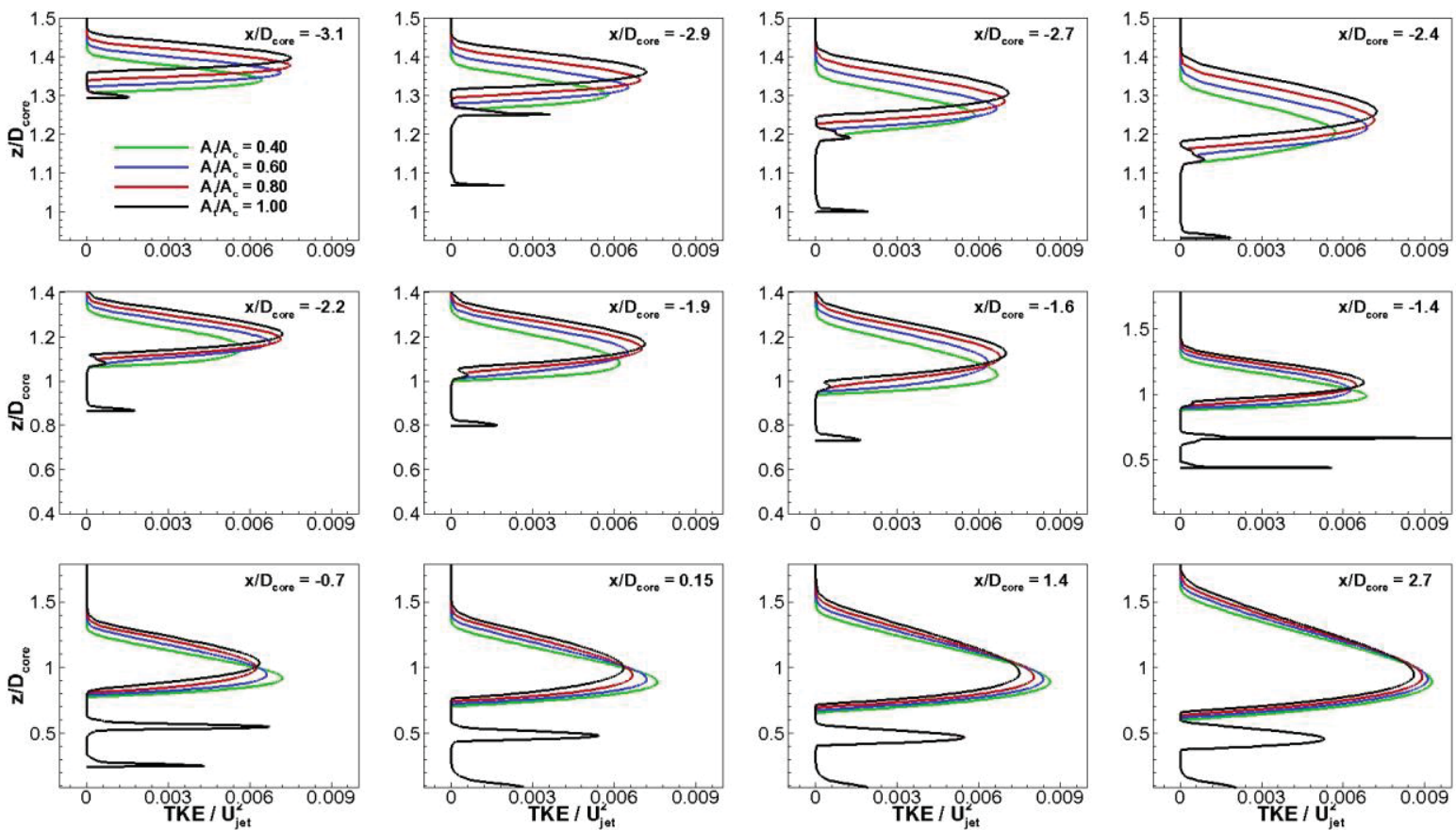

Figure 15. TKE profiles progressing from tertiary nozzle trailing edge to $2.7 \mathrm{D}_{\text {core }}$ downstream at $\left(A_{b} / A_{c}=1.75, N P R_{t}=1.6, N P R_{b}=N P R_{c}=1.8\right)$. Tertiary area ratios vary as $A_{t} / A_{c}=0.40,0.60,0.80$.

11

American Institute of Aeronautics and Astronautics 


\section{Bypass Area Variation}

Simulations were performed varying the bypass-to-core area ratio $A_{b} / A_{c}$ from 1.00, 1.75 and 2.50 by increasing the secondary exit area with a fixed core exit area. The design point with area ratio $A_{t} / A_{c}=0.80$ and pressure ratio $\mathrm{NPR}_{\mathrm{t}}=1.6, \mathrm{NPR}_{\mathrm{b}}=\mathrm{NPR}_{\mathrm{c}}=1.8$ was analyzed and TKE is plotted in Figure 16. Increasing the bypass-to-core area ratio elongates both the primary and secondary potential core and also results in a decrease in peak TKE.

The axial velocity profiles are plotted in Figure 17 and TKE profiles are plotted in Figure 18. The profiles are again taken at the previously analyzed stations. In the design process the flow lines were obtained by lengthening the plug downstream to increase the $A_{b} / A_{c}$ ratios and therefore the tertiary stream trailing edge location has also lengthened with increased bypass-to-core area ratio to meet the $A_{b} / A_{c}=2.50,1.75$ design space. At station $-3.1 D_{\text {core }}$ in Figure 17 the tertiary potential core is visible and for $A_{b} / A_{c}=2.50$ and the secondary potential core is also present in the profile. Increasing the secondary exit area decreased the outer tertiary shear layer with the ambient. The tertiary potential core merged with the secondary and increased the secondary potential core height and elongated the secondary potential core. Increasing the secondary area ratio decreases the outer shear layer thickness with the ambient after the tertiary has merged with the secondary potential core. At $-1.4 \mathrm{D}_{\text {core }}$ the increased secondary are ratio has impacted and decreased the primary potential core peak velocity. The trend of secondary on the primary potential core continues until $2.7 \mathrm{D}_{\text {core }}$. At station $-2.4 \mathrm{D}_{\text {core }}$ in Figure 18 the increase in area ratio has decreased the shear rate and thinned the shear layer resulting in a reduced TKE region and slightly reduced peak TKE. Lastly, the increase in secondary potential core length from increased area ratio has extended the secondary potential core length shielding the primary potential core significantly farther downstream than previously observed tertiary NPR and area ratio effects. The increase in bypass-to-core area ratio creates a decrease in shear rate and results in an increase in peak TKE.
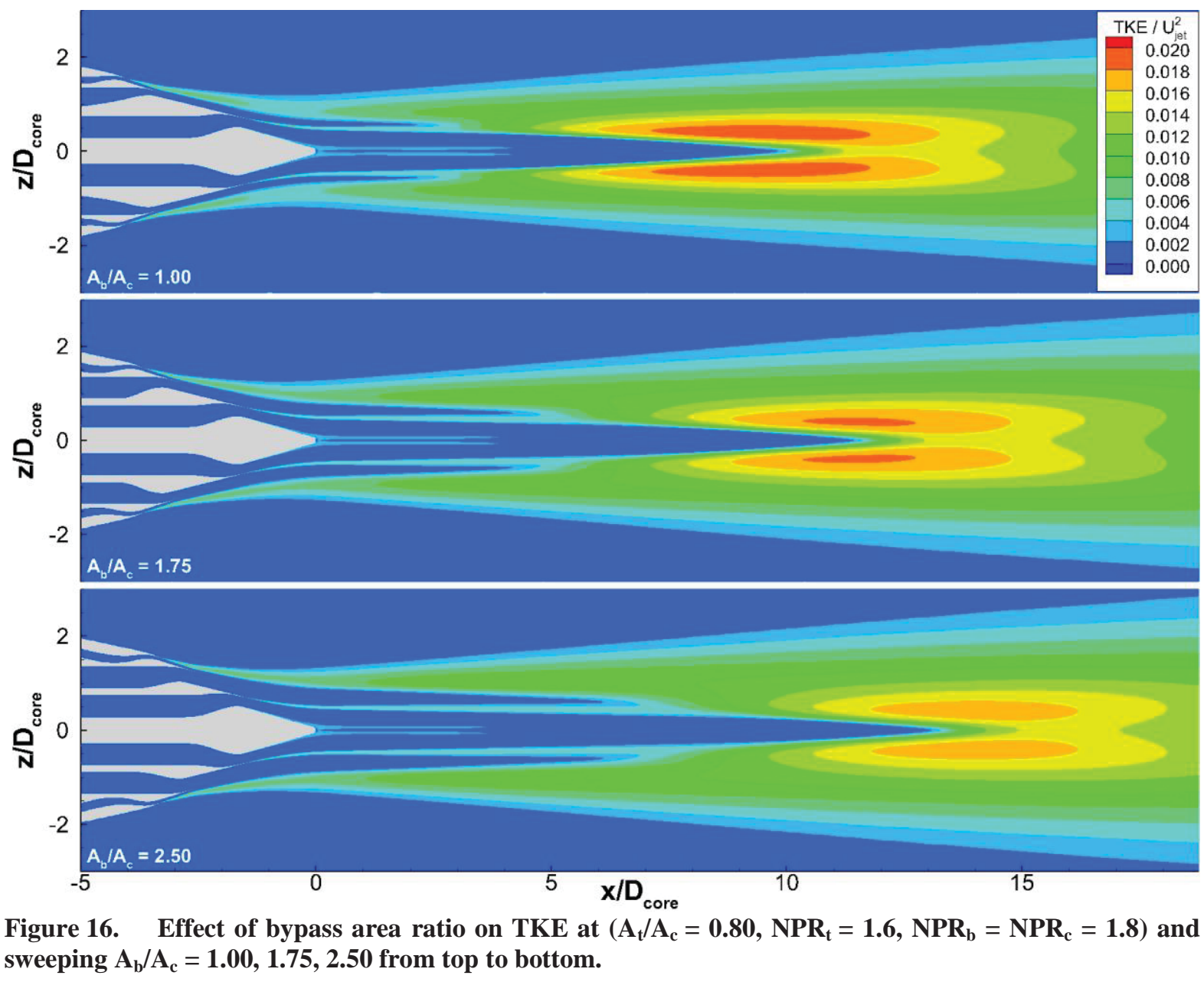

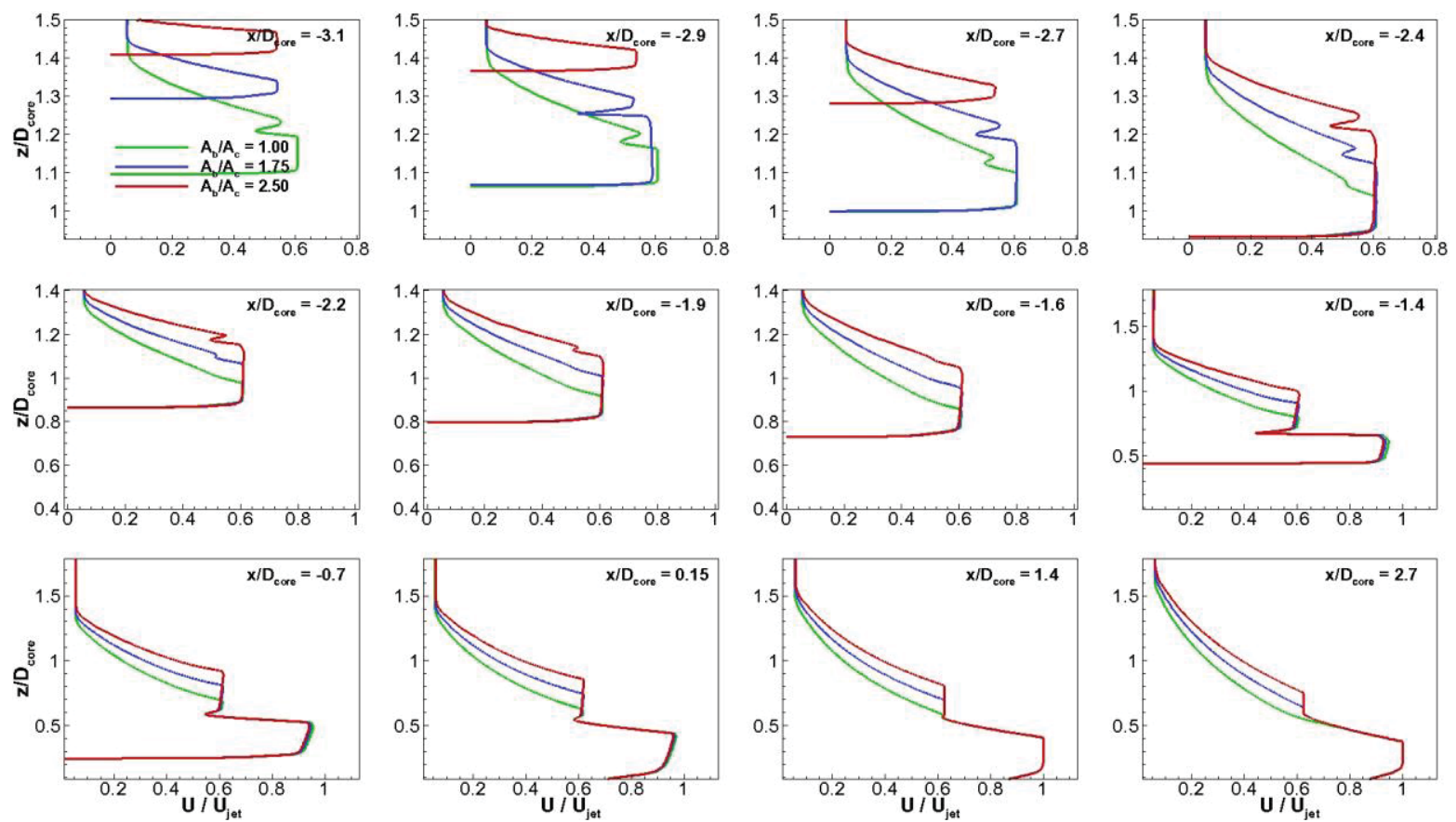

Figure 17. Velocity profiles progressing from tertiary nozzle trailing edge to $2.7 \mathrm{D}_{\text {core }}$ downstream at $\left(A_{t} / A_{c}=0.80, N P R_{t}=1.6, N P R_{b}=N P R_{c}=1.8\right)$. Bypass area ratios vary as $A_{b} / A_{c}=1.00,1.75,2.50$.
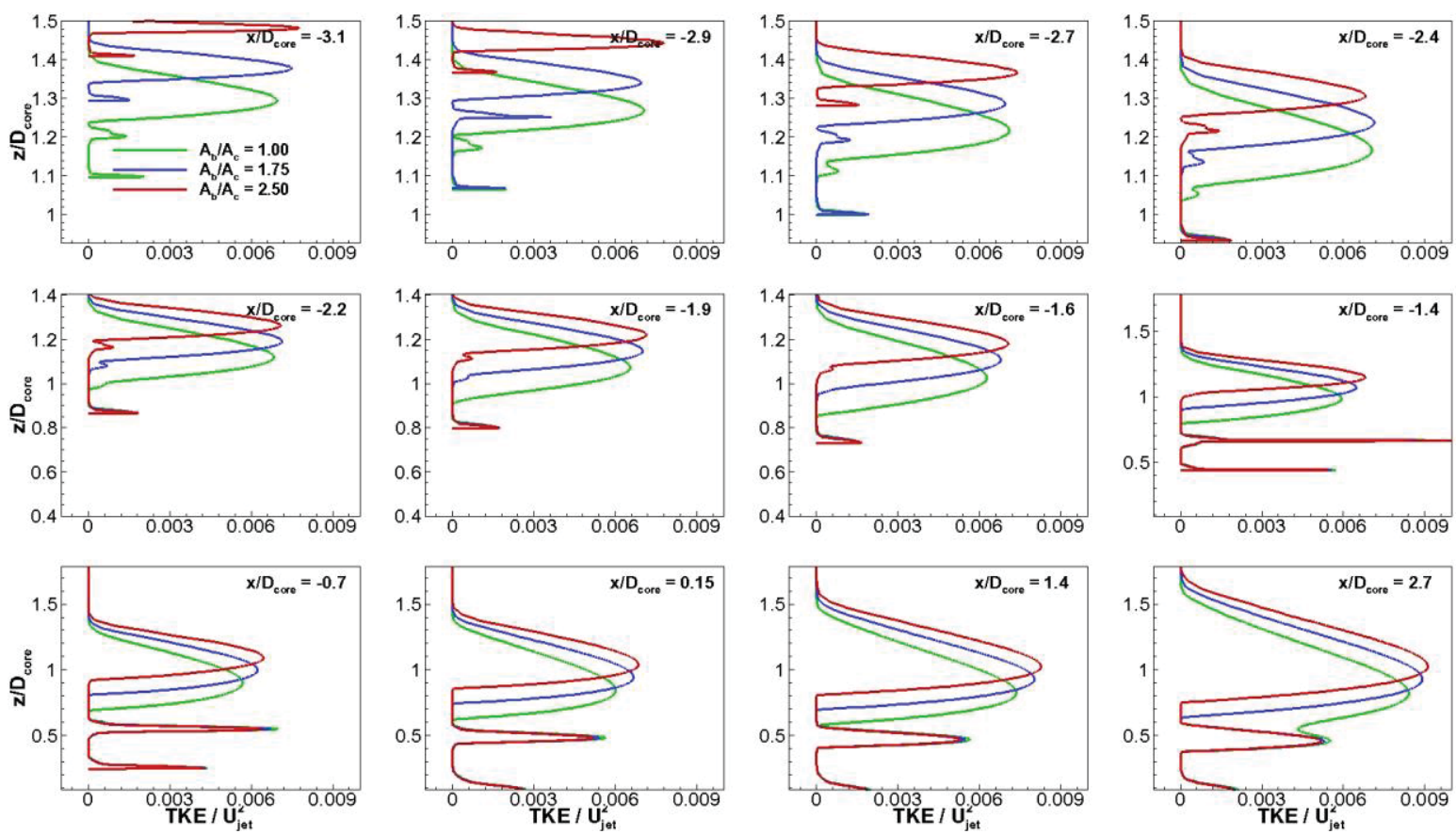

Figure 18. TKE profiles progressing from tertiary nozzle trailing edge to $2.7 \mathrm{D}_{\text {core }}$ downstream at $\left(A_{t} / A_{c}=0.80, N P R_{t}=1.6, N P R_{b}=N P R_{c}=1.8\right)$. Bypass area ratios vary as $A_{b} / A_{c}=1.00,1.75,2.50$. 


\section{E. Forward Flight Variation}

The impact of forward flight is of interest as both stationary runway and takeoff/landing community noise are important to modern nozzle design. A design point with area ratios $A_{b} / A_{c}=1.75, A_{t} / A_{c}=0.80$, and pressure ratios $\mathrm{NPR}_{t}=1.6, \mathrm{NPR}_{\mathrm{b}}=\mathrm{NPR}_{\mathrm{c}}=1.8$ was analyzed for varying freestream Mach number $\mathrm{M}_{\infty}=0.01,0.10,0.30$. The free jet Mach number effect on TKE is shown in Figure 19. As the freestream Mach number is increased the corresponding jet plume region narrows and elongates the primary potential core and reduces peak TKE. Forward flight effect is know to reduce turbulent mixing noise in jet exhaust.

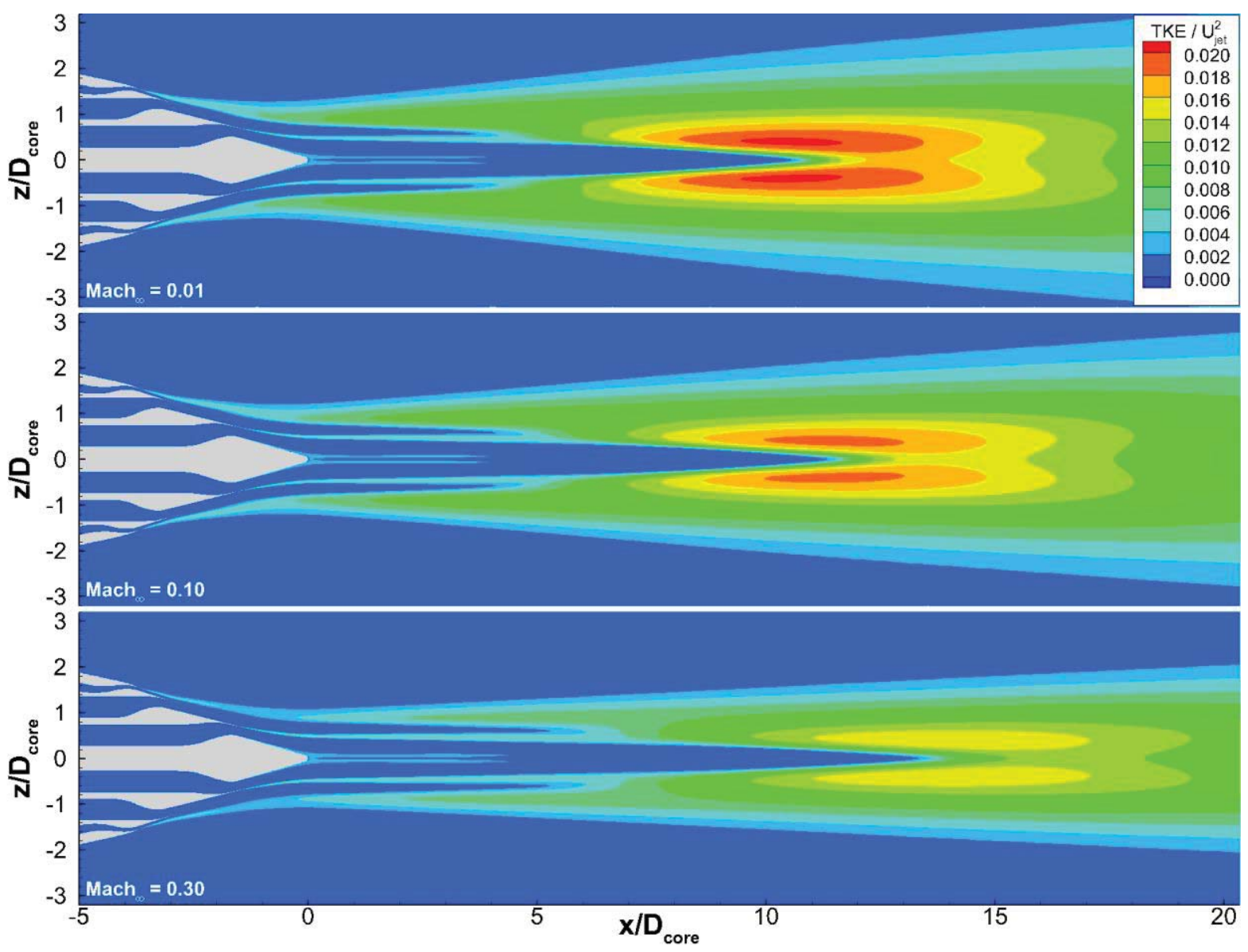

Figure 19. Effect of forward flight on TKE at $\left(A_{b} / A_{c}=1.75, A_{t} / A_{c}=0.80, N P R_{t}=1.4, N P R_{b}=N P R_{c}=\right.$ 1.8) and sweeping $M_{\infty}=0.01,0.10,0.30$ from top to bottom. 


\section{Acoustic Predictions}

\section{A. An Acoustic Analogy Method}

Jet noise predictions presented here are carried out using a RANS-based acoustic analogy approach available within the JeNo ${ }^{9,10}$ code. In the context of the generalized acoustic analogy, as proposed by Goldstein ${ }^{11}$, the governing acoustic equations are obtained by dividing Navier-Stokes (NS) equations into a set of non-radiating base flow equations, plus a set of linear equations for the radiating components of motion. By selecting a set of five appropriately defined variables, four of them non-linear, it is shown that the operator part of the acoustic equations resembles those obtained by linearizing the convective form of the Euler equations about a similar base flow. In addition, when the base flow is approximated as a locally parallel mean flow, factors on the left-hand side of the momentum and energy equations that explicitly depend on viscosity reduce to higher order terms, and are neglected. Subsequently, these equations are combined into a single third-order wave equation for pressure, referred to as the inhomogeneous Pridmore-Brown (PB) equation ${ }^{12}$.

The equivalent sources of sound are defined as the second-order stresses that appear on the right-hand side of the equation, and consist of velocity/velocity and velocity/temperature fluctuations. These two distinct sources are associated with the momentum flux and enthalpy flux in the turbulent jet. The solution to the PB equation is usually obtained in a frequency domain using Green's function (GF) approach. The volume sources are expressed as an auto-covariance function associated with turbulent stresses at two points separated in space and time. Experimental data, such as measurements by Bridges et al. ${ }^{13,14}$ are used to assist with the source modeling. The required scales are normally obtained from suitable variables in a RANS solution. For example, using standard RANS solvers with a $k-\varepsilon$ or $k$ - $\omega$ turbulence model we obtain the length- and time-scales as $\ell \sim k^{1.5} / \varepsilon$, and $\tau \sim k / \varepsilon$, respectively.

The intensity of the momentum-flux source component depends on the local kinetic energy of turbulence as provided by a RANS solver. The enthalpy-flux source term, on the other hand, requires a dedicated RANS solution ${ }^{10}$ that provides the variance in stagnation enthalpy. For reasons discussed by Khavaran et al. ${ }^{15}$ it is more convenient if the latter source strength were evaluated from an empirical model dependent on readily available mean flow variables, such as an appropriate function of the mean stagnation enthalpy.

Supersonic jets, when not perfectly expanded, emit broadband shock associated noise in addition to the usual turbulent mixing noise. Shock noise is generated when convecting turbulent eddies interact with the shock cell structure, and could dominate the spectra at high frequency and at upstream directivity angles. When a third stream is available, it may be exploited as a mechanism to control or weaken the shock cell structure and reduce the associated noise. A third stream is potentially capable of reducing the shear between a jet and the ambient. In addition, it may help with fluid concepts such as inverted velocity profile and/or heat shield. These latter concepts are usually considered useful in diverting turbulent mixing noise from the sideline direction.

As noted above, the propagation GF is evaluated for each pair of source/observer locations, and at all frequencies of interest. Aside from a limited number of closed-form asymptotic solutions in the low or high frequency limits, the GF calculation is usually carried out numerically. When possible, solving the adjoint form of the equation helps with computational efficiency. These computations could become very challenging in 3D jet flows, and a practical implementation remains an area of research in aero-acoustics. With an available RANS solution for the nozzle flow of interest, the remaining computational activity is devoted mainly to the propagation GF.

The acoustic spectrum for jet mixing noise is evaluated here using the JeNo code and according to equation (16) in Khavaran et al. ${ }^{15}$ This reference also details the latest development in modeling the enthalpy/velocity source term. 


\section{B. Acoustic Results}

Examples presented here are intended to illustrate the sensitivity of the prediction tool of choice "JeNo" to a selective number of parameters in a multi-stream jet exhaust. In the first place, we compare the acoustic emission in a two- vs. a three-stream nozzle configuration of equivalent exhaust thrust. The operating conditions and RANS predictions for the two nozzles of interest were presented earlier in Figures 7 and 8 . Figure 7 shows a reduction in jet exit velocity and primary core-length, and a reduction in the turbulent kinetic energy in the three-stream nozzle case compared to that of the two-stream exhaust is shown in Figure 8. Reduction in the core flow NPR between the two cases (from 1.8 in two-stream to 1.6 in three-stream), and introduction of a third-stream at a lower pressure ratio of $\mathrm{NPR}_{\mathrm{t}}=1.30$ works the same way as increasing the by-pass ratio in conventional two-stream nozzles with the introduction of a low speed secondary flow for thrust compensation. This concept provides the observed noise benefits in high-bypass ratio turbo-fan engines. Similar results are also predicted here as seen in Figure 20. The noise benefit is evident at all frequencies and all angles. All predicted spectra are shown as lossless, and on an arc at $60^{\circ}, 90^{\circ}, 120^{\circ}$ and 150 -deg from nozzle inlet.

The effect of varying the tertiary NPR on jet noise is investigated next. In this example, three cases are examined using fixed parameters of $\left(A_{b} / A_{c}=A_{t} / A_{c}=1.0, N_{c}=N P R_{b}=1.8\right)$ at an ambient Mach number of 0.10. The variable parameter is the third-stream pressure ratio that sweeps as $\mathrm{NPR}_{\mathrm{t}}=1.4,1.6,1.8$. Computational RANS results, presented earlier in Figures 9-12, correspond to similar three-stream configurations at a slightly larger tertiary area ratio of $A_{b} / A_{c}=1.75$. Subsequently mean velocity and turbulence discussions of section III-B hold bearing for this case as well. Velocity profile comparisons, at sections prior to the primary exhaust, show noticeable differences in the peak values for three cases (Figure 11). Downstream of the primary exhaust, there is little variation in the peak velocities among the three cases. Turbulence comparisons (Figure 12) also indicate increased turbulence near the exhaust in the tertiary with increasing $\mathrm{NPR}_{\mathrm{t}}$. Since turbulence scales (time and length) are the smallest in this vicinity, these differences in the tertiary flow result in additional high-frequency noise shown in the spectral predictions of Figure 21. The slight color difference visible in the contour-plots for TKE near $\mathrm{x} / \mathrm{D}_{\text {core }}=12$ (Figure 9) is not large enough to make a significant difference in predicted noise levels, and for all practical purposes the increase in low frequency noise is projected as $\sim 1.0 \mathrm{~dB}$ due to the slight increase in thrust.

The effect of tertiary area ratio variation on noise is considered next. In this example, two cases are examined using fixed parameters of $\left(\mathrm{NPR}_{\mathrm{c}}=\mathrm{NPR}_{\mathrm{b}}=\mathrm{NPR}_{\mathrm{t}}=1.80, \mathrm{~A}_{\mathrm{b}} / \mathrm{A}_{\mathrm{c}}=1.0\right)$ at an ambient Mach number of 0.10 . The tertiary area ratio sweeps as $A_{t} / A_{c}=0.60,1.0$. Computational RANS results, presented in Figures 13-15, although at a slightly different set of conditions $\left(\mathrm{NPR}_{t}=1.6\right.$ and $\left.\mathrm{A}_{\mathrm{b}} / \mathrm{A}_{\mathrm{c}}=1.75\right)$, indicate an increase in the mass flow (thrust) in the tertiary (Figure 14). Changes in turbulence level near the exit are relatively insignificant compared to the previous case discussed above. Subsequent changes in predicted spectra show a slight increase of $\sim 1.0 \mathrm{~dB}$ in low-tomid frequency noise due to an increase in nozzle thrust.

In the final example, we examine the effect of secondary area ratio on noise. Two cases are considered using fixed parameters $\left(\mathrm{NPR}_{\mathrm{c}}=\mathrm{NPR}_{\mathrm{b}}=1.80, \mathrm{NPR}_{\mathrm{t}}=1.40, \mathrm{~A}_{\mathrm{t}} / \mathrm{A}_{\mathrm{c}}=1.0\right)$ at an ambient Mach number of 0.10. The secondary area ratio sweeps as $A_{b} / A_{c}=1.0,2.50$. Computational RANS results, presented in Figures 16-18, represent a similar nozzle but at a slightly different conditions of $\left(\mathrm{NPR}_{t}=1.60\right.$ and $\left.\mathrm{A}_{t} / \mathrm{A}_{c}=0.80\right)$. It shows a reduction in peak TKE (Figure 16), an increase in mass flow rate and thrust in the secondary (Figure 17), and a slight increase in turbulence near the exit (Figure 18) with increasing the bypass area ratio. The net effect is projected as an increase in noise, up to 3.0dB in low-to-mid frequency (see Figure 23). This is mostly due to an increase in nozzle thrust in the secondary potential core. 


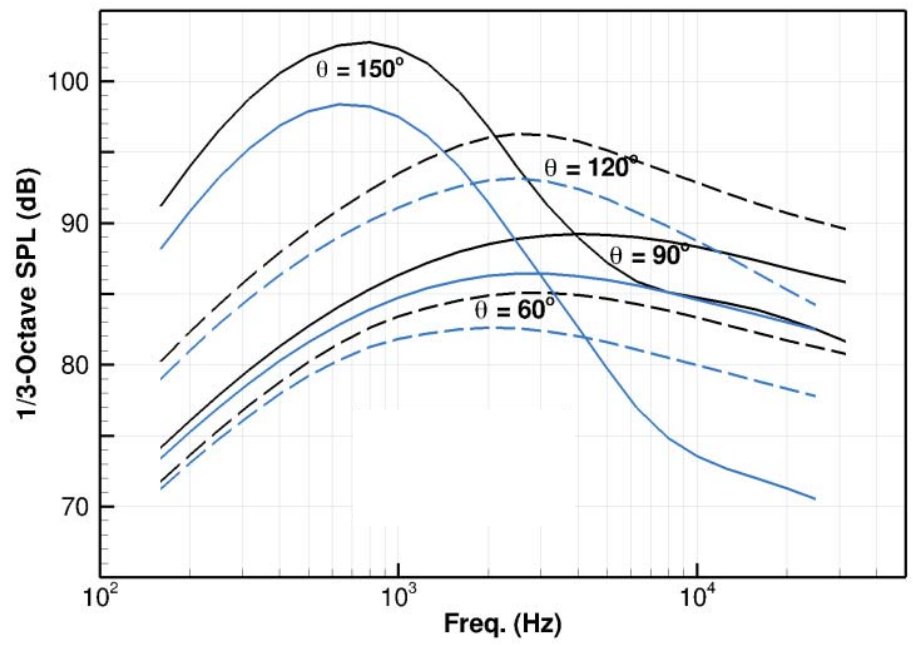

Figure 20. Acoustic spectra - comparing jets on equal mass flow rate basis: two-stream $\left(A_{b} / A_{c}=1.0, N P R_{c}=1.8, N P R_{b}=1.8\right)$ (dark) vs. threestream $\left(A_{b} / A_{c}=1.0, A_{t} / A_{c}=1.0, N P R_{c}=N P R_{b}=1.6, N P R_{t}=1.3\right)(b l u e)$

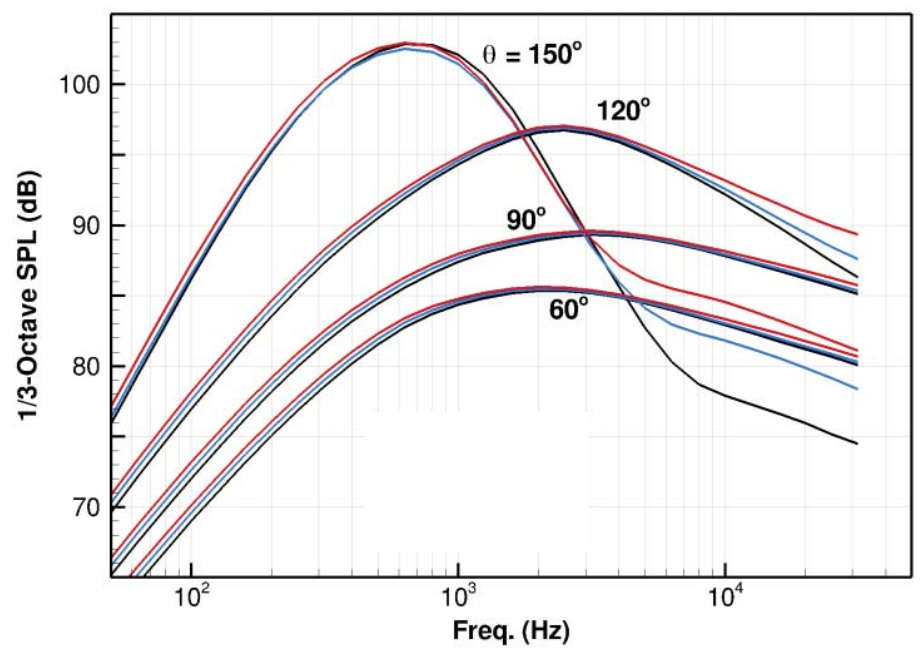

Figure 21. Acoustic spectra - comparing tertiary NPR variation in a three-stream nozzle at $\left(\mathrm{NPR}_{\mathrm{c}}=N P R_{\mathrm{b}}=1.80\right): \mathrm{NPR}_{\mathrm{t}}=1.40$ (dark), 1.60 (blue), 1.80 (red). 


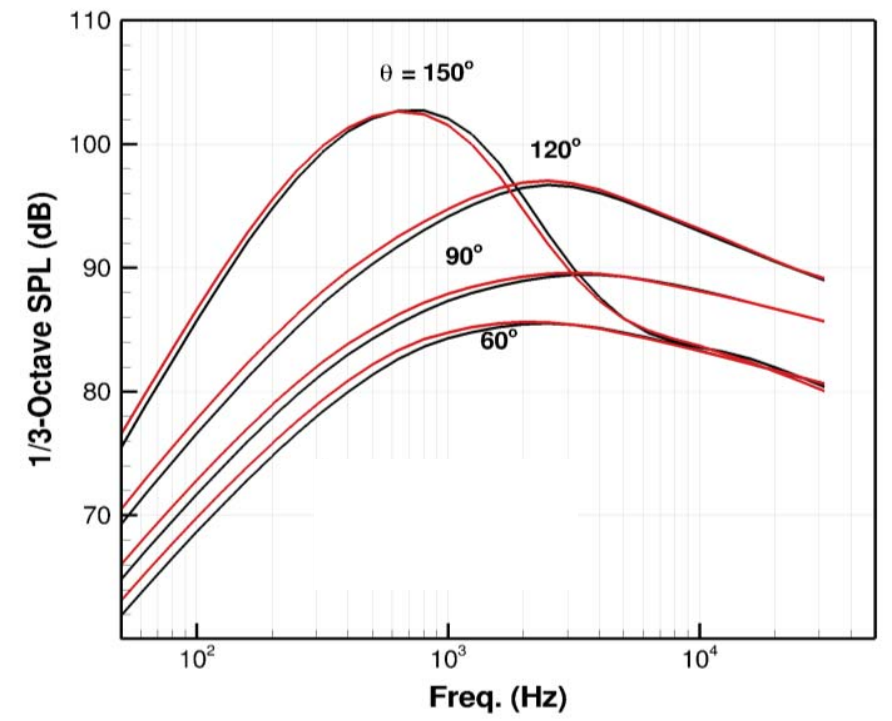

Figure 22. Acoustic spectra - comparing tertiary area variation in a three-stream nozzle at $\left(\mathrm{NPR}_{\mathrm{c}}=\mathrm{NPR}_{\mathrm{b}}=\mathrm{NPR}_{\mathrm{t}}=1.80, A_{\mathrm{b}} / \mathrm{A}_{\mathrm{c}}=1.0\right): \mathrm{A}_{\mathrm{t}} / \mathrm{A}_{\mathrm{c}}=0.60($ dark $), A_{t} / A_{c}=1.0$ (red).

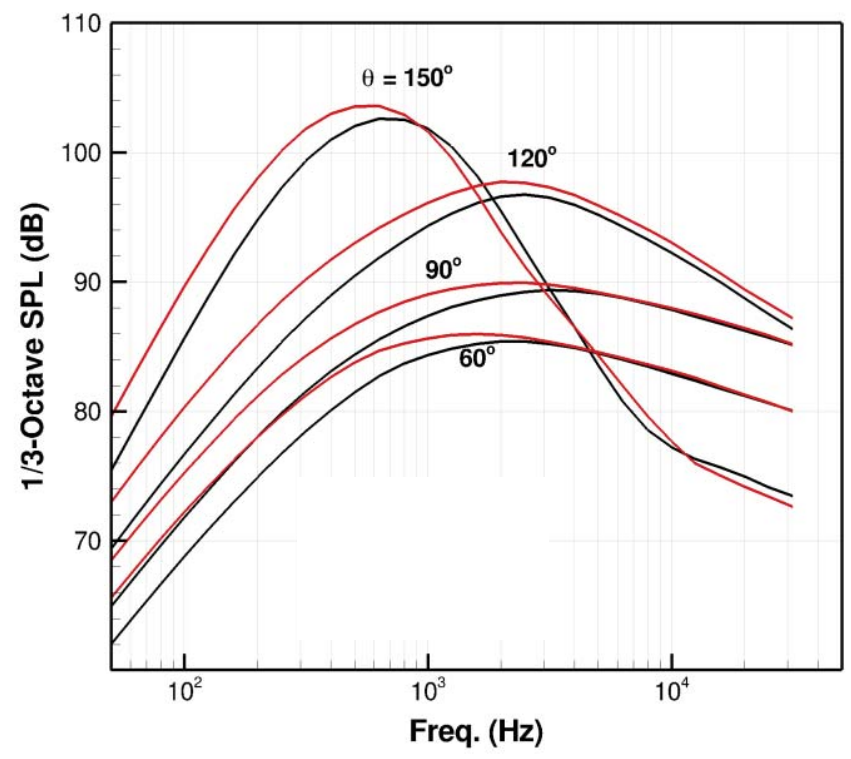

Figure 23. Acoustic spectra - comparing secondary area variation in a three-stream nozzle at $\left(\mathrm{NPR}_{\mathrm{c}}=\mathrm{NPR} \mathrm{R}_{\mathrm{b}}=1.80, \mathrm{NPR}_{\mathrm{t}}=1.40\right): \mathrm{A}_{\mathrm{b}} / \mathrm{A}_{\mathrm{c}}=1.0$ (dark), $\mathrm{A}_{\mathrm{b}} / \mathrm{A}_{\mathrm{c}}=2.50$ (red). 


\section{Conclusions}

Computational fluid dynamics combined with acoustic simulations have shown predictive capability in threestream nozzle designs. Similarities between dual-stream experimental and numerical results and three-stream computations have been shown to have comparable acoustic effects. The results of an equal mass flow rate dualstream and three-stream comparison showed a large reduction in sound spectra for the latter. The noise benefit was evident at all frequencies from nozzle inlet. The three-stream results show increasing the tertiary power setting decreases the shear rate and lowers peak TKE resulting in increased high frequency noise. As tertiary-to-core area ratio is increased the near nozzle exit shear layer enlarges, peak TKE reduces and a slight increase in low frequency noise was observed. The foremost impact on noise was observed as secondary-to-primary area ratio was increased. The results showed an enlarged secondary potential core, elongated primary potential core and increased peak TKE levels. A noise increase was expected due to an increase in performance (thrust) as the secondary exit area was increased. Lastly, results of the forward flight Mach number thinned the primary jet plume region and elongated the primary potential core reducing peak TKE.

\section{Acknowledgments}

This work was funded by the High Speed project under the Fundamental Aeronautics program.

\section{References}

\footnotetext{
${ }^{1}$ Dosanjh, D. S. "Flow and Noise Characteristics of Multi-Stream Coaxial Supersonic Jets," AIAA-81-1977, 1981.

${ }^{2}$ Henderson, B. "Aeroacoustics of Three-Stream Jets," AIAA-2012-2159, 2012.

${ }^{3}$ Bogey,C., Bailly, C., "Investigation of Sound Sources in Subsonic Jets Using Causality Methods on LES Data," AIAA20052885, 2005.

${ }^{4}$ Viswanathan,K., Czech, M., Lee, I., “Towards Prediction of Dual-Stream Jet Noise: Database Generation,” AIAA 2011-1030, 2011.

${ }^{5}$ Viswanathan,K., Czech, M., "Measurement and Modeling Effect of Forward Flight on Jet Noise,” AIAA Journal, Vol.49, No. 1, January 2011.

${ }^{6}$ Saxena,S., Morris, P., "Noise Predictions for High Subsonic Single and Dual-Stream Jets in Flight," AIAA 2012-2082, 2012.

${ }^{7}$ Benek, J.A., Buning, P., G., and Steger, J., L., “A 3-D CHIMERA Grid Embedding Technique,” AIAA-85-1523-CP July 1985.

${ }^{8}$ Nichols,R., Tramel, R., and Buning, P., "Solver and Turbulence Model Upgrades to OVERFLOW 2 for Unsteady and HighSpeed Applications," AIAA-2006-2824, June 2006.

${ }^{9}$ Khavaran, A., Bridges, J., and Georgiadis, N., "Prediction of turbulence-generated noise in unheated jets," Part 1: JeNo

Technical Manual, NASA/TM-2005-213827, July 2005.

${ }^{10}$ Khavaran, A., Kenzakowski, D. C., and Mielke-Fagan, A. F., "Hot jets and sources of jet noise,” International J.

Aeroacoustics, 9(4,5), 2010, pp. 491-532.

${ }^{11}$ Goldstein, M. E., "Relation between the generalized acoustic analogy and Lilley's contribution to aeroacoustics," International J. Aeroacoustics, 9(4, 5), (2010), pp. 401-418.

${ }^{12}$ Pridmore-Brown, D. C., "Sound propagation in a fluid flowing through an attenuating duct," J. Fluid Mech. 4, pp. 393-406, 1958.

${ }^{13}$ Bridges, J., and Wernet, M. P., "Measurements of the aeroacoustic sound source in hot jets," AIAA-2003-3130, May 2003.

${ }^{14}$ Bridges, J., "Effect of heat on space-time correlation in jets," AIAA-2006-2534, May 2006.

${ }^{15}$ Khavaran, A., and Bridges, J., "An empirical temperature variance source model in heated jets," NASA/TM-2012-217743, 2012.
} 